\title{
Endocannabinoids and cortical plasticity: CB1R as a possible regulator of the excitation/inhibition balance in health and disease
}

\author{
Lucas J. A. Durieux ${ }^{\dagger}$, Sara R. J. Gilissen ${ }^{\dagger} \&$ Lutgarde Arckens*
}

KU Leuven, Department of Biology, Laboratory of Neuroplasticity and Neuroproteomics, 3000 Leuven,

$$
\text { Belgium }
$$

Leuven Brain Institute, Leuven, Belgium

\section{Joint first authors}

* Corresponding author: Lutgarde Arckens, Ph.D., Laboratory of Neuroplasticity and Neuroproteomics, Katholieke Universiteit Leuven, Naamsestraat 59, box 2467, B-3000 Leuven, Belgium tel: 0032 16323951,E-mail: lut.arckens@kuleuven.be

Running title: CB1R, cortical plasticity and excitation/inhibition balance

Keywords: Cannabinoids; Neocortex; Neuroplasticity; Schizophrenia; E/I balance

Special issue call for papers: 'Cannabinoid Signaling in the Brain: New Vistas'

Number of pages: 30

Number of words in the manuscript: 6570

Number of words in the abstract: 244

Number of figures: 5

Number of tables: 1

This article has been accepted for publication and undergone full peer review but has not been through the copyediting, typesetting, pagination and proofreading process, which may lead to differences between this version and the Version of Record. Please cite this article as doi: $\underline{10.1111 / \text { ejn. } 15110}$

This article is protected by copyright. All rights reserved 


\section{Abstract}

The endocannabinoid system has been linked to neurological disorders in which the excitation inhibition (E/I) balance of the neocortex is dysregulated, such as schizophrenia. The main endocannabinoid receptor type 1 of the central nervous system - CB1R - is expressed on different cell types, that when activated, modulate the cortical E/I balance. Here we review how CB1R signalling contributes to phases of heightened plasticity of the neocortex. We review the major role of the CB1R in cortical plasticity throughout life, including the early life sensory critical periods, the later maturation phase of the association cortex in adolescence, and the adult phase of sensory deprivationinduced cortical plasticity. Endocannabinoid-mediated long-term potentiation and depression of synapse strength fine-tune the E/I balance of visual, somatosensory and association areas. We emphasize how a distinct set of key endocannabinoid-regulated elements such as GABA and glutamate release, basket parvalbumin interneurons, somatostatin interneurons and astrocytes, are essential for normal cortical plasticity and dysregulated in schizophrenia. Even though a lot of data has been gathered, mechanistic knowledge about the exact CB1R-based modulation of excitation and/or inhibition is still lacking depending on cortical area and maturation phase in life. We emphasize the importance of creating such detailed knowledge for a better comprehension of what underlies the dysregulation of the neocortex in schizophrenic patients in adulthood. We propose that taking age, brain area and cell type into consideration when modulating the cortical E/I imbalance via cannabinoid-based pharmacology may pave the way for better patient care.

This article is protected by copyright. All rights reserved 


\section{Introduction}

The endocannabinoid system is involved in brain development as well as plasticity and has been implicated in developmental brain disorders such as schizophrenia and Autism Spectrum Disorder (Leweke et al., 2018; Schultz et al., 2019). Aberrant plasticity processes underlying such neurological disorders are often related to a change in excitation-inhibition (E/I) balance in cortical brain regions (Ramamoorthi \& Lin, 2011; Moretto et al., 2018). These observations emphasize the importance of understanding how (endo)cannabinoids influence the E/I balance in the neocortex, potentially in an age-dependent manner, and as such possibly contribute to contradictory effects in health and diseased conditions. In this review we will focus on the role of excitation and inhibition in different phases of cortical plasticity throughout life, highlighting the endocannabinoid system as a regulator, in an effort to better characterize how this may relate to neurological disorders such as schizophrenia and may hold the key towards developing better treatments.

Schizophrenia appears caused by malfunctioning of a brain-wide network that includes associative as well as primary sensory cortices (van den Heuvel \& Fornito, 2014). Although a lot of research focusses on the role of the prefrontal cortex, it is hypothesized that grey matter abnormalities in schizophrenia may start in parietal and occipital cortices (Yildiz et al., 2011). Primary somatosensory (parietal) and visual (occipital) cortices may be involved, as well as the posterior parietal cortex, an association region that integrates information from the different senses. Association cortices like the posterior parietal cortex and the prefrontal cortex functionally mature during adolescence (Caballero et al., 2014; Piekarski et al., 2017; Larsen \& Luna, 2018). This is the exact period in life where the abuse of exogenous cannabinoids leads to an increased risk to develop psychosis, as seen in schizophrenia (Andréasson et al., 1987; Arseneault, 2002; van Os et al., 2002; Zammit et al., 2002; Manrique-Garcia et al., 2012).

The maturation of the sensory cortices precedes the maturation of association cortices and consists of what is called early life 'critical periods'. These phases of heightened plasticity are induced and closed by an increase in inhibition and occur at different postnatal ages for the different primary senses (Fig. 1) (Hensch, 2005; Hensch \& Bilimoria, 2012; Reh et al., 2020). In rodents for example, the critical period of the somatosensory cortex takes place during the two weeks following birth

This article is protected by copyright. All rights reserved 
(Erzurumlu \& Gaspar, 2012) while in the visual cortex the critical period appears later, between postnatal days 19 and 32 (Gordon \& Stryker, 1996). Each of the sensory plasticity windows is closed before adolescence is reached, but can be reinstated later on in adulthood, by rejuvenating the inhibitory system, when inhibitory levels have reached a plateau typical for adulthood. Typical effective strategies are pharmacological suppression of inhibition and sensory/housing manipulations such as dark exposure (Huang et al., 2010). Yet reinstating the critical period in mouse sensory cortex during adolescence appears impossible. These observations support the view that during adolescence sensory plasticity appears crystalized, at a time when association cortex is shaped into a mature state (Fig. 1).

The endocannabinoid system has been implicated in regulating critical periods of plasticity in sensory and associative cortices. In visual cortex, endocannabinoids are necessary for the maturation of the inhibitory system, reflecting a possible capability to pharmacologically shift the critical period (Jiang et al., 2010; Abbas Farishta et al., 2015; Begum \& Sng, 2017). In adolescence, different components of the endocannabinoid system are influenced by pubertal hormones and are differently expressed in both sexes, factors that also contribute to cortical plasticity and the occurrence of schizophrenia (for review: Viveros et al., 2011; Craft et al., 2013; Hillard, 2015; Wagner, 2016).

Taken together, in this review we want to highlight the relevance of knowing how endocannabinoids influence cortical plasticity periods to better understand how disorders like schizophrenia come about, how cannabis influences the brain and how cannabinoid-based treatments should be designed differently depending on a patient's age. In this review we will therefore discuss the role of the endocannabinoid system in cortical plasticity from early life to adulthood, via its influence on excitation and inhibition, and how this can create knowledge towards better treatments for neurological disorders such as Schizophrenia.

This article is protected by copyright. All rights reserved 


\section{Excitation and inhibition}

The $\mathrm{E} / \mathrm{I}$ balance is a tightly regulated process in the brain that is adjusted when the firing activity of different brain cells changes. In order to function properly, the right balance between excitation and inhibition has to be implemented in the brain networks. In its most simple form the E/I balance is adaptable at the synapse level as determined by the release strength of either $\gamma$-aminobutyric acid (GABA; inhibition) or Glutamate (excitation). Each cell is characterized by its own E/I balance, as defined by its excitatory and inhibitory synaptic contacts. Release of neuromodulators, such as endocannabinoids, will lead to synaptic plasticity for example under the form of long-term potentiation (LTP) and long term depression (LTD). Changes in the E/I balance may thus involve changes in the relative activity of different types of excitatory and inhibitory neurons. From a largescale perspective, the E/I balance can be described as the sum of excitatory and inhibitory inputs resulting in a specific output intensity. The output intensity of a microcircuit or of global cortical activity will therefore depend on the local connectivity and the synaptic strength between excitatory pyramidal cells and inhibitory interneurons. The E/I balance thus refers to a stable global activity level in a given network. As such the E/I balance may represent an organizing framework for understanding findings related to pathophysiology. Summarizing current knowledge about what endocannabinoid signaling can achieve in relation to altering excitation, inhibition and the E/I balance at cell-specific and microcircuit level is the focus of this review.

\section{The cortical endocannabinoid system}

Endocannabinoids act via two main receptors, $\mathrm{CB} 1 \mathrm{R}$ and $\mathrm{CB} 2 \mathrm{R}$. While CB2R is mainly expressed in peripheral tissues, $\mathrm{CB} 1 \mathrm{R}$ is mostly present in the central nervous system and responsible for endocannabinoid effects in the brain (for review Piomelli, 2003). With regard to the endocannabinoid signaling machinery, two main neuron-derived ligands of the CB1R are 2-Arachidonoylglycerol (2AG) and Anandamide (Fig. 2A and 2B). Anandamide is a fatty acid, synthesized from the cleavage of its precursor $\mathrm{N}$-arachidonoyl-phosphatidylethanolamine by phospholipase D. 2-AG can be produced in two different ways with the same precursor in common, known as phosphatidylinositol (PI). PI's hydrolysis is catalysed by phospholipase A1 which forms Lyso-PI. Lyso-PI is then hydrolised in 2-

This article is protected by copyright. All rights reserved 
AG by Lyso-PLC. PI can also be cleaved through the catalysis of a phospholipase resulting in 1,2diacylglycerol then converted in 2-AG by diacylglycerol lipase (DAGL $\alpha$ and DAGL $\beta$ ). Both anandamide and 2-AG have their own enzymatic degradation pathway with respectively the serine hydrolase fatty amide hydrolase (FAAH) and monoglyceride lipase (MAGL) (Fig. 2A and 2B).

Cortical cell-specific expression of the CB1R is only partially described. Most studies report CB1R exclusively on GABAergic interneurons (Bodor et al., 2005; Hill et al., 2007), but there are studies that include its presence on excitatory neurons. In embryonic stages, the CB1R is already expressed by pyramidal cells at E13.5 and only at a later stage in GABAergic interneurons (Berghuis et al., 2007; Mulder et al., 2008; Wu et al., 2010). In adult rodents, CB1R mRNA has been detected in nonGABAergic cells (Marsicano \& Lutz, 1999) in the forebrain of the mouse and RT-PCR proved the expression of the receptor in $49 \%$ of rat sensorimotor cortex pyramidal neurons (Hill et al., 2007). Expression of the CB1R on excitatory neurons in visual cortex and motor cortex is also described by the Allen brain atlas ("Brain Map - brain-map.org," 2020).

Cortical GABAergic interneurons consist of many different subtypes, with parvalbumin- (PV; Fig. 3 in purple) and somatostatin (SOM; Fig. 3 in green)-positive interneurons as the main types. Interneurons have much more CB1R expression than excitatory neurons. In rodents, the majority of CB1R expressing cells are cholecystokinin-positive interneurons (Fig. 3 in orange; Marsicano \& Lutz, 1999; Bodor et al., 2005), followed by calbindin-positive interneurons. Nevertheless, other interneuron subtypes have also been described as CB1R expressing. In the sensorimotor cortex of rats, up to respectively $63 \%$ and $69 \%$ of the SOM- and vasoactive intestinal polypeptide (VIP)-expressing interneurons express CB1R mRNA (Hill et al., 2007). Recently, single-cell RNA sequencing allowed the subdivision of 16 interneuron subclasses in the mouse visual cortex (Zeisel et al., 2015). The sequencing data, and the related online tool (http://innarssonlab.org/cortex/), confirm high expression of CB1R mRNA in 4 cholecystokinin-positive interneuron subclasses, but also reveal other GABAergic cell markers co-expressed with CB1R mRNA, namely VIP, Htr3a, ReIn and Calbindin mRNA. This is further confirmed by the visual cortex transcriptomics data set from the Allen brain institute ("Brain Map - brain-map.org," 2020). Even if PV is not part of this list of cell markers, $\mathrm{PV}^{+}$ interneurons have been shown to be sensitive to CB1R ligands (Jiang et al., 2010) and the experience-

This article is protected by copyright. All rights reserved 
induced maturation of their inhibitory synapses appears regulated by CB1R ligands (Huang \& Kirkwood, 2020). With CB1R on many different interneuron classes, indirect modulation of $\mathrm{PV}^{+}$ interneurons, by disinhibition for example, is a highly likely possibility.

Apart from neuronal expression, the CB1R is also expressed on astrocytes (Fig. 3 in blue). Astrocytes are the most abundant glial cells in the central nervous system, which can shape synapse development and maturation (Clarke \& Barres, 2013) and modulate synaptic transmission thanks to the release of gliotransmitters (Perea et al., 2009). This makes them key players in plasticity and regulation of the $\mathrm{E} / \mathrm{I}$ balance of the cortex. Evidence for CB1R expression by astrocytes is accumulating, as well as the presence of the ECB synthesis machinery, indicating astrocytes as a non-neuronal source of 2-AG and Anandamide (for review see: Metna-Laurent \& Marsicano, 2015; Oliveira da Cruz et al., 2016). For mouse visual cortex, the Allen brain database detects CB1R mRNA in astrocytes, although much lower compared to neural cell types. Even if the level of expression appears extremely low, astroglial CB1R function seems essential in modulating cortical long-term plasticity (Min \& Nevian, 2012).

CB1R is thus present in inhibitory and excitatory neurons, as well as astrocytes, and capable of modulating their function. This is not completely unexpected, since during embryonic development, endocannabinoids are required for the neurochemical differentiation of pyramidal, cholinergic, astroglial and GABAergic cells (Aguado et al., 2006; Berghuis et al., 2007; Mulder et al., 2008; Keimpema et al., 2013). Therefore, they appear capable of shaping or influencing the different cellular components that settle the E/I balance throughout life from very early on into adulthood.

With regard to the endocannabinoid system, the E/I balance is mainly influenced via post-synaptic activity-dependent release of on-demand produced endocannabinoids, which activate pre-synaptic CB1Rs, thereby inhibiting GABA and Glutamate release (Fig. 2) (Shen et al., 1996; Kreitzer, 2002; Chen et al., 2010; Szabo et al., 2014). This short term retrograde signaling, known as depolarizationinduced suppression of inhibition and depolarization-induced suppression of excitation, regulates synaptic communication and thus synaptic plasticity (Fig. 2). This short-term plasticity is mediated by the inhibition of calcium $\left(\mathrm{Ca}^{2+}\right)$ influx in the presynaptic terminal, and therefore exocytosis, while endocannabinoid-driven long-term plasticity is mediated by down regulation of the cAMP/PKA pathway (Piomelli, 2003; Heifets \& Castillo, 2009). Astroglial CB1R activation increases the 
intracellular $\mathrm{Ca}^{2+}$ level that triggers the release of glutamate. In the hippocampus this leads to the modulation of long term-potentiation (LTP) and long-term depression (LTD) of the synaptic transmission (Han et al., 2012; Gómez-Gonzalo et al., 2015). In the cortex the knowledge is scarce but once released glutamate activates pre-synaptic N-methyl-D-aspartate (NMDA) receptor and promotes spike timing-dependent long-term depression (Fig 4, Min \& Nevian, 2012).

\section{Endocannabinoid-mediated early critical periods in neocortex}

Historically, the visual system has been used for unraveling the mechanisms behind experiencedependent critical period plasticity. Hubel and Wiesel were the first to demonstrate that loss of visual input during the critical period, via lid suture, results in the development of poor vision through that eye. Cortical territory serving the sutured contralateral eye is taken over by the open ipsilateral eye, inducing the so-called ocular dominance (OD) shift (Wiesel \& Hubel, 1965; Le Vay et al., 1980; Wiesel, 1982). OD plasticity peaks at P26-28 in mice. The neuronal circuitry then becomes consolidated and the capacity for plasticity becomes more constraint, and even shortly crystalized during adolescence (Fig. 1; (Huang et al., 2010; Nys et al., 2014, 2015).

A large body of evidence has indicated that maturation of GABAergic synaptic inhibition is crucial for the onset of the critical period (Hensch et al., 1998; Fagiolini \& Hensch, 2000; Morales et al., 2002a). Mice lacking the synaptic isoform of the GABA synthetizing enzyme glutamic acid decarboxylase $\left(\mathrm{GAD}_{65}\right)$ fail to exhibit a visual critical period. Diazepam, a drug that increases postsynaptic responses at active inhibitory synapses, overrules the $\mathrm{GAD}_{65}$ knockout phenotype (Fagiolini \& Hensch, 2000). The maturation of inhibitory innervation is attributed to visual experience: the total number of GABAergic synapses undergoes a threefold increase between eye opening and the end of the critical period (Morales et al., 2002b; Chattopadhyaya et al., 2004; Jiang et al., 2005).

Fast-spiking basket $\mathrm{PV}^{+}$interneurons can directly inhibit pyramidal neurons at the soma and thus refine and control the excitability of the cortical network (Fig. 3, purple). They have a delayed maturation matching with the opening of the critical period related to heightened plasticity. They are progressively enwrapped with a perineural net, promoting the uptake of OTX2 to open and close 
critical periods (Levelt \& Hübener, 2012; Reh et al., 2020). Inducing early maturation of the basket $\mathrm{PV}^{+}$interneuron population, by premature removal of polysialic acid, altering Brain Derived Neurotrophic Factor (BDNF) or OTX2 levels, leads to a premature opening of the critical period (Hanover et al., 1999; Di Cristo et al., 2007; Sugiyama et al., 2008). Basket $\mathrm{PV}^{+}$cells are however not exclusively responsible for the critical period. $\mathrm{SOM}^{+}$interneurons are also thought to have their importance. They can inhibit both $\mathrm{PV}^{+}$interneurons and pyramidal neurons, especially at their distal dendrites (Fig.3, green; Yavorska \& Wehr, 2016) Their maturation is happening when critical period plasticity reaches its peak (Scheyltjens \& Arckens, 2016). Abolishing $\mathrm{SOM}^{+}$cell activity via hM4DiDREADD receptors during the critical period impedes the normal maturation of binocular visual cortex by impairing the maturation of ipsilateral eye inputs. Transplanting embryonic $\mathrm{SOM}^{+}$precursor cells into P7 visual cortex can induce a second de novo cortical plasticity window, just like embryonic $\mathrm{PV}^{+}$precursor cells can (Tang et al., 2014; Yaeger et al., 2019).

The switch between an immature plastic visual cortex and a mature more resistant visual cortex with age is thus supported by an evolution of the E/I balance, and specifically LTD-mediated GABAergic maturation (Fig. 1). Endocannabinoids mediate this phenomenon, as supported by anatomical, geneediting, electrophysiological and pharmacological evidence (Jiang et al., 2010).

In mice in which the gene encoding for $\mathrm{CB} 1 \mathrm{R}, \mathrm{Cnr} 1$, has been knocked-out $(\mathrm{Cnr} 1 \mathrm{KO})$ the primary visual cortex (V1) does not reach a normal shape: V1 is abnormally rounded while it should be more oval according to the difference in the ovality index between adult CB1R KO and control mice (Fig. 4, Abbas Farishta et al., 2015). This abnormal shape in Cnr1 KO mice goes hand in hand with a narrower visual field representation, specifically along the horizontal axis. Basic visual neuronal response characteristics, considered critical to establish visual perception, such as contrast sensitivity and spatial frequency area also affected in $\mathrm{Cnr} 1 \mathrm{KO}$ mice. The immunohistochemical distribution of the CB1R in the visual cortex is area- and visual experience-dependent. The extragranular layers of the secondary visual areas medial and lateral to V1 express more CB1R, and dark rearing reduces the CB1R expression (Yoneda et al., 2013), indicative for an involvement of CB1R in the anatomical and functional organization of this sensory cortex.

This article is protected by copyright. All rights reserved 
Evidence arises that the endocannabinoid system is specifically involved in L2/3 and L5 but not L4 when it comes to synaptic plasticity. Long-term depression (LTD; Fig. 5) of excitatory neurotransmission induced in L2/3 by low frequency stimulation is not affected by inhibitors of PKA or $\alpha$-amino-3-hydroxy-5-methyl-4-isoxazolepropionic acid receptor endocytosis as in L4, but is reliably blocked by the highly potent CB1 receptor antagonist AM251 (Crozier et al., 2007). Monocular deprivation-induced synaptic depression in vivo occludes both L2/3 and L4 LTD, strongly suggesting that different mechanisms contribute to the effects of monocular deprivation in different layers of mouse visual cortex.

Many forms of plasticity at GABAergic transmission onto pyramidal neurons have been elucidated and plasticity at GABAergic synapses is proposed to contribute to neural circuit refinement and functional maturation of the cortex (Maffei, 2011; Le Magueresse \& Monyer, 2013) Endocannabinoid-mediated LTD of GABAergic neurotransmission (iLTD, Fig. 5) can be induced in L2/3 of rat visual cortex, suggesting that endocannabinoids are crucial for the maturation of GABAergic inputs (Huang et al., 2010; Jiang et al., 2010). Also in mice, endocannabinoid-mediated iLTD can be induced in L2/3 and L5 pyramidal neurons in a particular lamina-specific postnatal period, but not in L4 star pyramidal neurons at any postnatal age. Dark rearing delays the developmental loss of endocannabinoid-mediated iLTD in both L2/3 and L5 during a critical period, which could be eliminated in both layers by 2 days of light exposure. Visual experience thus drives the closure of the critical period of iLTD, mediated by a loss of responsiveness to endocannabinoids (Fig. 1) (Fig. 4; Sun et al., 2015). Furthermore, in Cnr1 KO mice, the GABAergic synapses in L2/3 and L5 do not normally mature whereas those in L4 develop normally.

A similar experience-dependent cortical development has been documented for the other sensory modalities. In the somatosensory modality of rodents for example, a reallocation of cortical territory due to altered whisker inputs is easily observable. The primary somatosensory cortex contains barrelshaped domains in L4 of the somatosensory cortex, with neurons in a given barrel responsive to inputs from a single whisker. These cortical domains start processing specific somatosensory information during the critical period based on experience (Fox, 1992; Erzurumlu \& Gaspar, 2012).

This article is protected by copyright. All rights reserved 
Just like with deprivation of visual inputs, trimming whiskers early in life leads to a disturbed development of the barrel maps in somatosensory cortex (Erzurumlu \& Gaspar, 2012).

The CB1R is expressed in the barrel cortex. Sixteen days after birth, CB1R immunoreactivity is high in L2/3, L5 and L6, but not in L4, a layer distribution similar to the one found in the visual cortex, and with CB1R immunostainings allowing to distinguish the negative barrel forms in cortical L4 (Deshmukh et al., 2007). This distribution pattern could predict that CB1R signaling is involved in the early cortical plasticity process (Fig. 1), permitting the development of proper somatosensory whisker-barrel maps. Pharmacological blocking of the CB1R with the AM251 antagonist during the critical period, enlarges $\mathrm{S} 1$ area activation by individual whiskers, inducing a decreased receptive field specificity (Fig. 4; Li et al., 2009). This abnormal maturation of the cortical whisker map has also been highlighted by genetic deletion of the CB1R gene Cnr1, leading to a reduced barrel map area, barrel domain and in-between barrel septal area (Fig. 4; Hedrich et al., 2020).

Moreover, Cnr1 KO leads to a disturbed development of cortico-thalamic and thalamo-cortical axons to and from S1. The observed phenotype results in misrouted thalamo-cortical axons and abnormally large axon bundles for both cortico-thalamic and thalamo-cortical connectivity (Fig. 4; Wu et al., 2010). Interestingly, a constitutive $\mathrm{KO}$ of $\mathrm{Cnr} 1$ has a different effect whether the gene deletion targets all the cells of the forebrain or only a specific cell type. A full KO reduces the septal space between barrels, while a Cnr1 KO targeting glutamatergic neurons enlarges this morphological parameter, and no changes are observed when specifically targeting GABAergic cells (Hedrich et al., 2020). This opposite effect between full and glutamatergic $\mathrm{KO}$ of $\mathrm{Cnrl}$ could reflect that yet another cell type is involved in the endocannabinoid-mediated maturation of the S1 map. In this context, confirmation of the astroglial CB1R involvement in barrel cortex plasticity has been achieved by focusing on a specific kind of plasticity, the spike timing-dependent depression (t-LTD; Fig. 4 and 5). When t-LTD is induced by excitatory postsynaptic potentials paired with a preceding postsynaptic evoked action potential, it results in an increase in $\mathrm{Ca}^{2+}$ in nearby astrocytes. Clamping of $\mathrm{Ca}^{2+}$ in astrocytes blocks the t-LTD as well as gliotransmitter release (Min \& Nevian, 2012). This proves the involvement and requirement of endocannabinoid-sensitive astrocytes in synaptic plasticity of the barrel cortex. Bath application of the antagonist AM251 can prevent the $\mathrm{Ca}^{2+}$ changes in astrocytes while agonist WIN has the opposite effect on the astrocytic $\mathrm{Ca}^{2+}$. These observations implicate astrocytes in excitatory

This article is protected by copyright. All rights reserved 
synaptic plasticity of the barrel cortex through endocannabinoids and CB1R. This interplay with excitatory synapse plasticity is in line with astrocytes being crucial elements at the tripartite synapse, both structurally and functionally.

More evidence for participation of $\mathrm{CB} 1 \mathrm{R}$ in somatosensory cortex plasticity can be deduced from the impact of its pharmacological manipulation on the strength of neuronal communication. AM251 antagonism, when coupled to whisker input deprivation, impedes the weakening of L2/3-L4 synapses normally induced by the sensory deprivation ( $\mathrm{Li}$ et al., 2009). CB1R regulation of S1 synapses has also been confirmed by studying L5 pyramidal neurons of the barrel cortex, where application of the same CB1R antagonist on thalamo-cortical slices can prevent post-synaptic potentials and LTP, whereas the CB1R agonist WIN has the opposite effect and facilitates post-synaptic potentials (Maglio et al., 2018). This has been observed after both thalamic neuron and basal dendrite stimulation.

Even though association cortex maturation happens later in life, during adolescence, the endocannabinoid system can already control the prefrontal E/I balance early in life. Bath application of the WIN agonist for example reduces excitatory post-synaptic potentials in 17 day-old rat prefrontal cortex slices while the antagonist SR141716A (SR) induces the opposite effect (Auclair et al., 2000) Involvement of endocannabinoids in prefrontal cortex synapse plasticity during development has also been proven by its effect on LTD (Fig. 4). Application of a tetanic stimulation can lead to LTD or LTP, the probability could be shifted in favor of LTD by applying WIN and shifted in favor of LTP with SR antagonism (Fig. 5) (Auclair et al., 2000).

\section{Adolescence and endocannabinoid-mediated cortical maturation}

Plasticity during the adolescent phase of life is understudied compared to developmental or adult brain plasticity. The plastic period during adolescence is related to more complex experiences like social interactions, sexual maturation and higher cognitive functions. Although this occurs when sensory cortex plasticity has largely ceased, the critical period of association cortex is, just as primary sensory critical periods, characterized by the maturation of the GABAergic inhibitory system as well

This article is protected by copyright. All rights reserved 
as similar endocannabinoid-based modulations (Caballero et al., 2014; Piekarski et al., 2017; for review, Larsen \& Luna, 2018).

An upregulation of the dopamine system, BDNF expression and puberty hormones have been put forward as triggers for the adolescent critical period (Webster et al., 2002; Arain et al., 2013; Caballero et al., 2016; Du et al., 2018). All these factors can be modulated by the endocannabinoid system, putting this modulatory system forward as a potential important player of adolescent plasticity (Chiu et al., 2010; Yeh et al., 2017) . During adolescence, and due to pubertal hormones, our body changes dramatically, for example due to muscle growth, increase of height and sexual maturation. These body changes inevitably cause the need for our cortical body maps, initially developed in the early life critical period of somatosensory cortex, to adapt. These adaptations will come about via plasticity. Dysregulation of the map plasticity, possibly also already in early life, may explain a maladaptive refinement of the somatosensory and parietal cortex and explain why schizophrenic patients can experience a self-disturbance characterized by a disturbed sense of self-awareness and selfhood (Sass, 2013). The involvement of puberty hormones in the process could also reflect why schizophrenia is more common in males than females, due to oestrogen levels protecting females.

When the E/I balance matures in the prefrontal cortex, the GABAergic system undergoes changes such as shifts in GABA receptors density, adaptations in interneuron marker expressions like PV and calretinin, and neuromodulatory regulation (Tseng \& O'Donnell, 2007; Hashimoto et al., 2009; Caballero et al., 2014; Cass et al., 2014). Like for the somatosensory and visual cortices, the endocannabinoid system has been investigated in the regulation of the $\mathrm{E} / \mathrm{I}$ balance and the development of the prefrontal cortex.

A 3-week intraperitoneal treatment of adolescent rats with the CB1R - CB2R agonist CP55,940 leads to a disturbed morphology of $\mathrm{L} 2 / 3$ pyramidal neurons in the adult prefrontal cortex, reflected in a decreased dendritic length, arbor number and complexity (Renard et al., 2016). The same agonist regime can also reduce LTP in the prefrontal cortex when hippocampal area CA1 is stimulated, thus corroborating previous results indicating that activating the endocannabinoid system with its agonist CP55,940 reduces excitatory postsynaptic current (Fig. 4 and 5) (Lafourcade et al., 2007). Bath application of the AM251 antagonist can block LTD in the prefrontal cortex in 4-6 week-old mice

This article is protected by copyright. All rights reserved 
(Lafourcade et al., 2007; Lovelace et al., 2015). It is known that LTD can require metabotropic GluR 2/3 (mGluR2/3) activity, and this mGluR2/3-mediated long-term plasticity appears to be reduced in the prefrontal cortex of mice treated with WIN (Fig. 4). Also, endocannabinoid-mediated LTD is prevented when mGluR5 is blocked with 2-Methyl-6-(phenylethynyl)pyridine or MPEP (Lafourcade et al., 2007; Lovelace et al., 2015). These observations reflect interconnections between endocannabinoids and long-term plasticity of the excitatory glutamatergic neurotransmitter system in adolescent association cortex. A role for endocannabinoids in the maturation of the E/I balance of the prefrontal cortex is also revealed by the diminution of spontaneous GABAergic inhibitory postsynaptic currents in adult rats after treatment with WIN during adolescence (Cass et al., 2014). The same treatment does not induce the same outcome in adulthood, again pointing out that endocannabinoids certainly have a major role in GABAergic maturation of the prefrontal cortex during adolescence, and that this role is limited to this particular time window in life.

\section{Endocannabinoids and adult cortical plasticity}

In adulthood, the sensory neocortex is capable of a plastic response, especially after loss of sensory inputs due to injury or disease. For example, late-onset vision loss due to monocular enucleation, a mouse model for unilateral vision loss mimicking human patients following ophthalmic trauma, inflammation, injury or enucleation as a common treatment for end-stage glaucoma, retinoblastoma or Phthisis bulbi (a shrunken, non- functional eye) (Moshfeghi et al., 2000; Setlur et al., 2010; Aerts et al., 2014), causes a functional reorganization of the otherwise normally developed visual cortex. The deprived binocular cortex becomes dominated by the ipsilateral spared eye as in early life ocular dominance plasticity. Intriguingly, the deprived monocular cortical territory undergoes cross-modal plasticity. Whiskers become a dominant input source and drive a take-over of the monocular visual cortex for somatosensation, resembling the use of visual cortex for braille reading in the blind. This cross-modal plasticity process does not occur at an adolescent age (P45) and coincides with an upregulation of the alpha-1 subunit of the $\mathrm{GABA}_{\mathrm{A}}$ receptor (Van Brussel et al., 2011; Nys et al., 2014).

This article is protected by copyright. All rights reserved 
The same cell types with a prominent role in early sensory critical periods, the $\mathrm{PV}^{+}$and $\mathrm{SOM}^{+}$ interneurons as well as the astrocytes, also play a prominent role in adult cortical plasticity. Local optogenetic activation of the $\mathrm{SOM}^{+}$neurons prior to monocular enucleation prevents the deprived visual cortex to become sensitive to whiskers (Scheyltjens et al., 2018). Astrocytes also present themselves as fast responders after monocular enucleation, required for adult plasticity in the mouse visual cortex Astrocyte activation via the Gi-DREADD approach can even boost the plasticity process (Hennes et al., 2020). In monocular deprivation studies, activation of the inhibitory VIP-SOM interneuron motive, through optogenetic stimulation of $\mathrm{VIP}^{+}$neurons, leads to increased activity in the primary visual cortex (Fu et al., 2014, 2015).

More evidence for a role for the basket $\mathrm{PV}^{+}$type of interneurons comes from applying short dark exposure periods to adult rodents, a process that can reintroduce ocular dominance plasticity (He et al., 2006, 2007). Dark exposure leads to the potentiation of evoked $\mathrm{PV}^{+}$IPSCs in the auditory cortex (Petrus et al., 2015). Reintroducing light to adult animals after a dark exposure period leads to degradation of the perineural nets surrounding $\mathrm{PV}^{+}$interneurons in the mature visual cortex, thereby freeing space for new synaptic contacts (Murase et al., 2017). When dark exposure is applied in combination with WIN agonism, the ocular dominance shift appears reduced, indicating that the CB1R is either involved in or a target to modulate adult visual cortex plasticity (Huang et al., 2010).

Compared to visual cortex, current knowledge about adult somatosensory cortex plasticity appears limited. Yet again, the GABAergic system seems central since whisker trimming in adult rats leads to a decreased expression of the $\mathrm{GABA}_{\mathrm{A}}$ receptor (Fuchs \& Salazar, 1998). Increased sensory stimulation of specific whiskers of the adult mouse results in a transient increased immunoreactivity of the GABA synthesizing enzyme glutamic acid decarboxylase, localized to the cortical representation of the relevant whisker follicles (Welker et al., 1989).

In adult prefrontal cortex, bath application of the CB1R antagonist AM251 can block LTD, just as in adolescent mice (Lafourcade et al., 2007; Lovelace et al., 2015). Inhibiting monoacyglycerol lipase (MAGL, Fig. 2) - an enzyme that normally contributes to the hydrolysis of 2-AG - increases LTD, while inhibition of the synthesis of 2-AG results in blocking this type of long-term plasticity (Fig. 4; Lafourcade et al., 2007; Martin et al., 2015). The prefrontal cortex is clearly still sensitive to 
cannabinoids in adulthood, which is promising for possible therapeutic targeting of this neurotransmitter system after the onset of E/I related disorders such as schizophrenia.

For now, there is hardly any information available correlating endocannabinoids to adult cortical plasticity. It is however known that the expression of CB1R mRNA levels or the binding capacity of this receptor changes throughout life. In rodents, it is established that the binding capacity increases and peaks right before puberty, to then decline and stabilize into adulthood (Rodríguez de Fonseca et al., 1993; Wang et al., 2003; Di Marzo et al., 2015). A further decline characterizes ageing, possibly in regard to protecting pyramidal neurons against neurodegeneration and inflammation, via the GABAergic interneurons (Albayram et al., 2011). In adult human brain there were remarkable differences for cannabinoid binding sites between, primary, secondary and association regions, with association regions having the highest density of cannabinoid receptors (Glass et al., 1997).

Taken together, this CB1R activity peak at puberty onset, preceded and followed by lower binding during periods of early and adult plasticity, is potentially related to the adolescent critical period and the regulation of top down and bottom up processing of sensory information and experience. The level of attention that is given to a certain stimulus is related to the strength of the bottom-up input as well as to brain state. Both processes involve gamma brain wave oscillations (Garcia-Rill, 2017).

They are related with information processing in cortical networks and can decrease in power via CB1R agonism. Cannabis users show decreased gamma waves, similar to the disturbance of these waves in schizophrenia, which may correlate with cannabis-induced altered perception (Skosnik et al., 2014, 2016). Administration of cannabinoids in critical developmental stages disrupts synchronization of neural oscillation in adulthood. This effect might be one of the main mechanisms in which cannabinoids induce attention, working memory and motor-sensory integration disturbances, which all relate to psychosis-related behavior.

\section{Cortical plasticity: insights into schizophrenia}

Disruptions of the endocannabinoid system underlying schizophrenia have been extensively described (for review please see Zamberletti et al., 2012; Fakhoury, 2017). CB1R and ligand expression are different in the brain of schizophrenic patients (Dean et al., 2001), and polymorphism of the Cnr1

This article is protected by copyright. All rights reserved 
gene is detected for the hebephrenic type of schizophrenia (Ujike et al., 2002; Chavarría-Siles et al., 2008). The contribution also surfaces in rodent models of schizophrenia, in which there is a decrease of the CB1R expression in the prefrontal cortex (Gomes et al., 2018; Borgan et al., 2020). Stressing the putative role of CB1R in schizophrenia even further, cannabis use during adolescence results in a higher risk of developing neuropsychiatric disorders, notably increasing the chance of showing psychotic schizophrenic-spectrum disorders (Andréasson et al., 1987; Arseneault, 2002; van Os et al., 2002; Zammit et al., 2002; Manrique-Garcia et al., 2012). However, cannabis is considered a risk factor for revealing predisposition to schizophrenia and not as a direct causal factor to this condition. The role of endocannabinoid signaling in the development and maturation of the prefrontal cortex during adolescence is also of particular interest, since adolescence is a vulnerability period for addiction and neuropsychiatric disorders, and the main cannabis-derived phytocannabinoid is a CB1R agonist (For review, Saito et al., 2013; Hurd et al., 2014).

Six endocannabinoid-regulated elements we deemed central in prompting cortical plasticity throughout life, appear deregulated in schizophrenia: GABA release, glutamate release, the E/I balance, basket $\mathrm{PV}^{+}$interneurons, $\mathrm{SOM}^{+}$interneurons and astrocytes, and will be briefly discussed.

Deficits in inhibitory communication are thought to reinforce schizophrenia since numerous GABAergic parameters are downregulated. Indeed, there is a decrease in the mRNA of the GABA synthesizing enzyme $\mathrm{GAD}_{67}$, indicative of a reduced availability of presynaptic GABA in the cortex of schizophrenic patients (Gonzalez-Burgos et al., 2011). Inhibition from basket $\mathrm{PV}^{+}$and chandelier $\mathrm{PV}^{+}$interneurons is altered (Ferguson \& Gao, 2018). By innervating the perisomatic region of pyramidal neurons, basket $\mathrm{PV}^{+}$cells are strategically positioned to exert feedforward inhibition as well as gain control. Basket $\mathrm{PV}^{+}$cells have also been implicated in the generation of gamma oscillations, and gamma waves are disturbed in schizophrenic patients (Skosnik et al., 2016). These interneurons have a decreased expression of $\mathrm{PV}$ and $\mathrm{GAD}_{67}$ and an increased expression of the opioid receptor $\mu$, which can suppress the GABA release (Fig. 3, middle grey box). At the post-synaptic site of especially L3/4 pyramidal neurons there is a decrease of the alpha-1 subunit of the $\mathrm{GABA}_{\mathrm{A}}$ receptor. Regulation of basket $\mathrm{PV}^{+}$cell activity by other interneurons, in disinhibition motives, impacts the activity in this basket PV-pyramidal neuron microcircuit. $\mathrm{SOM}^{+}$interneurons are such modulating interneurons that target distal dendrites of pyramidal neurons and basket $\mathrm{PV}^{+}$cells, and 
are also abnormal in schizophrenia, displaying a decreased expression of the SOM neuropeptide and the SOM receptor 2 mRNA in post-mortem cortical tissue (Fig. 3, upper grey box) (Morris et al., 2008, 2008; Fung et al., 2010; Beneyto et al., 2012). The combination of such alterations at pre- and postsynaptic sites results in weakened inhibition of cortical pyramidal neurons in schizophrenic patients.

Concerning the glutamatergic system, a possible glutamatergic NMDA receptor hypofunction and a disturbed excitatory neuronal communication is emphasized in schizophrenic patients. A treatment with an NMDA receptor antagonist induces enhanced positive symptoms without creating new ones. In healthy subjects, treatment with the same compound induces the mimicking of schizophrenic psychotic and cognitive abnormalities (Tamminga, 1999; Ross et al., 2006). Even though the reported NMDA receptor hypofunction and a downregulated GABAergic system can seem contradictory, Lisman (2012) nicely explains that NMDA receptor-reduced activity might cause downregulation of inhibition. NMDA receptor hypofunction might be sensed by GABAergic neurons as a reduced glutamatergic cell activity, and thus the need to reduce the inhibition transmission accordingly. Disturbance of pyramidal neuron functionality could thus be a driver of the deficits seen for basket $\mathrm{PV}^{+}$cells, via a lowering of their excitatory drive to basket $\mathrm{PV}^{+}$cells. More research is needed to settle whether or not manifestation of schizophrenia really needs disturbance in both cell types. Reduced excitatory neuron function might lead to inhibitory circuit compensations and vice versa. This might even involve subtype-specific interneurons and may lead to a pathological switch in circuit function and behavior (e.g. hallucinations) based on specific cellular deficits and specific aspects of circuit activity (e.g. oscillations). Since endocannabinoids can influence both sides of the E/I balance, they can have different roles and lead to different outcomes in several pathologies. The exact modulations that endocannabinoids bring about to the $\mathrm{E} / \mathrm{I}$ balance for each pathology remain to be discovered.

Astrocyte dysfunction in schizophrenia is under investigation but for now results are difficult to reproduce and still too diverse to create a clear picture (for review see Bernstein et al., 2015; Mei et

al., 2018). For instance, the expression of astrocytic excitatory amino acid transporter 2 is reported to be decreased, not altered or even increased in patient post-mortem tissue (Hu et al., 2015). Knowing the importance of astrocytes in the maturation and regulation of the cortical E/I balance, we propose

This article is protected by copyright. All rights reserved 
to refine future research by considering age (Fig. 1) and astrocyte diversity as factor. The recently reported astrocyte diversity across brain areas, and even between the cortical layers, is promising and may hold the key to disentangle the exact contributions of possibly only certain subtypes of astrocytes to cortical plasticity as well as psychiatric and neurological disorders (Batiuk et al., 2020; Bayraktar et al., 2020). The diversity of astrocytes could explain the low expression of CB1R in this cell type and its expression on specific subtypes that would be abnormal in schizophrenia should be investigated ("Brain Map - brain-map.org," 2020). Schizophrenia research concentrating on the cortical sensory areas is underrepresented compared to association cortex, although they are also affected. For now, most evidence comes from studying sensory perception and not from plasticity studies. Somatosensory and visual cortices have been shown to reach a non-optimal functional state in schizophrenic patients. Patients show poor performance in tasks, with deficits in visual processing of stimulus characteristics like contrast and shape discrimination, resembling some of the features that have been reported about the impact of $\mathrm{Cnr} 1 \mathrm{KO}$ on visual perception in rodents (see above; Butler et al., 2008; Abbas Farishta et al., 2015). In terms of neurobiological measurement, patients have a reduced visual cortex volume and neuronal density, they also show a reduced amount of GABA in visual cortex. Regarding somatosensory performance, schizophrenic patients present deficits in touch discrimination and proprioception, which has been linked with abnormal evoked potentials in the somatosensory cortex, disturbed timing of these potentials and mis-localized evoked field responses to touch stimuli. These sensory cortex deficits might also all reflect an abnormal development or plasticity regulation of sensory cortices already early in life, related to irregular endocannabinoid signaling in the different critical periods of cortical plasticity.

\section{Conclusion and open questions}

In sum, the involvement of CB1R and endocannabinoid signaling in the maturation and life-long control of the cortical E/I balance is not to be doubted considering the evidence reviewed here. Future research will have to go further in understanding the key role of endocannabinoids in these phenomena. The increased knowledge will hopefully help tackling the disturbed E/I balance in the

This article is protected by copyright. All rights reserved 
context of brain disorders through precise and effective endocannabinoid- and CB1R-based pharmacology, which can only be made available by taking all variables into consideration. There are however important questions remaining that need to be considered in future research. (1) How different is the role of endocannabinoids in cortical synapse plasticity throughout different and consecutive phases of life? (2) Could this explain why endocannabinoid treatment strategies for neurological disorders give conflicting results? (3) Will the refining of our knowledge about the cortical endocannabinoid system and factors such as age, sex, neocortical area and cell subtype open up opportunities to refine or rethink current treatments and lead to patient-tailored endocannabinoidbased pharmacology? Even if knowing more about the role of endocannabinoids in normal cortical development, maturation and experience-dependent plasticity will not have a direct impact on treatments of neurological disorders, it will lead to the gathering of fundamental mechanistic insights about cortical plasticity. Besides its importance to comprehend disease conditions, such knowledge will without a doubt be relevant in the context of brain plasticity induction as a treatment for brain injury or sensory loss.

This article is protected by copyright. All rights reserved 


\section{References}

Abbas Farishta, R., Robert, C., Turcot, O., Thomas, S., Vanni, M.P., Bouchard, J.-F., \& Casanova, C. (2015) Impact of CB1 Receptor Deletion on Visual Responses and Organization of Primary Visual Cortex in Adult Mice. Investigative Opthalmology \& Visual Science, 56, 7697.

Aerts, J., Nys, J., \& Arckens, L. (2014) A Highly Reproducible and Straightforward Method to Perform In Vivo Ocular Enucleation in the Mouse after Eye Opening. Journal of Visualized Experiments,

Aguado, T., Palazuelos, J., Monory, K., Stella, N., Cravatt, B., Lutz, B., Marsicano, G., Kokaia, Z., Guzmán, M., \& Galve-Roperh, I. (2006) The Endocannabinoid System Promotes Astroglial Differentiation by Acting on Neural Progenitor Cells. J. Neurosci., 26, 1551-1561.

Albayram, O., Alferink, J., Pitsch, J., Piyanova, A., Neitzert, K., Poppensieker, K., Mauer, D., Michel, K., Legler, A., Becker, A., Monory, K., Lutz, B., Zimmer, A., \& Bilkei-Gorzo, A. (2011) Role of CB1 cannabinoid receptors on GABAergic neurons in brain aging. Proc Natl Acad Sci U S A, 108, 1125611261 .

Andréasson, S., Engström, A., Allebeck, P., \& Rydberg, U. (1987) CANNABIS AND

SCHIZOPHRENIA A Longitudinal Study of Swedish Conscripts. The Lancet, Originally published as Volume 2, Issue 8574, 330, 1483-1486.

Arain, M., Haque, M., Johal, L., Mathur, P., Nel, W., Rais, A., Sandhu, R., \& Sharma, S. (2013) Maturation of the adolescent brain. Neuropsychiatr Dis Treat, 9, 449-461.

Arseneault, L. (2002) Cannabis use in adolescence and risk for adult psychosis: longitudinal prospective study. BMJ, 325, 1212-1213.

Auclair, N., Otani, S., Soubrie, P., \& Crepel, F. (2000) Cannabinoids Modulate Synaptic Strength and Plasticity at Glutamatergic Synapses of Rat Prefrontal Cortex Pyramidal Neurons. Journal of Neurophysiology, 83, 3287-3293.

Batiuk, M.Y., Martirosyan, A., Wahis, J., de Vin, F., Marneffe, C., Kusserow, C., Koeppen, J., Viana, J.F., Oliveira, J.F., Voet, T., Ponting, C.P., Belgard, T.G., \& Holt, M.G. (2020) Identification of 
region-specific astrocyte subtypes at single cell resolution. Nature Communications, 11, 1220.

Bayraktar, O.A., Bartels, T., Holmqvist, S., Kleshchevnikov, V., Martirosyan, A., Polioudakis, D., Ben Haim, L., Young, A.M.H., Batiuk, M.Y., Prakash, K., Brown, A., Roberts, K., Paredes, M.F., Kawaguchi, R., Stockley, J.H., Sabeur, K., Chang, S.M., Huang, E., Hutchinson, P., Ullian, E.M., Hemberg, M., Coppola, G., Holt, M.G., Geschwind, D.H., \& Rowitch, D.H. (2020) Astrocyte layers in the mammalian cerebral cortex revealed by a single-cell in situ transcriptomic map. Nature Neuroscience, 23, 500-509.

Begum, M.R. \& Sng, J.C.G. (2017) Molecular mechanisms of experience-dependent maturation in cortical GABAergic inhibition. J Neurochem, 142, 649-661.

Beneyto, M., Morris, H.M., Rovensky, K.C., \& Lewis, D.A. (2012) Lamina- and cell-specific alterations in cortical somatostatin receptor $2 \mathrm{mRNA}$ expression in schizophrenia.

Neuropharmacology, Schizophrenia, 62, 1598-1605.

Berghuis, P., Rajnicek, A.M., Morozov, Y.M., Ross, R.A., Mulder, J., Urbán, G.M., Monory, K., Marsicano, G., Matteoli, M., Canty, A., Irving, A.J., Katona, I., Yanagawa, Y., Rakic, P., Lutz, B., Mackie, K., \& Harkany, T. (2007) Hardwiring the Brain: Endocannabinoids Shape Neuronal Connectivity. Science, 316, 1212-1216.

Bernstein, H.-G., Steiner, J., Guest, P.C., Dobrowolny, H., \& Bogerts, B. (2015) Glial cells as key players in schizophrenia pathology: recent insights and concepts of therapy. Schizophrenia Research, White Matter Pathology, 161, 4-18.

Borgan, F., Kokkinou, M., \& Howes, O. (2020) The Cannabinoid CB1 Receptor in Schizophrenia. BPS: CNNI, $\mathbf{0 .}$

Brain Map - brain-map.org [WWW Document] (2020) . URL https://portal.brain-map.org/

Butler, P.D., Silverstein, S.M., \& Dakin, S.C. (2008) Visual Perception and Its Impairment in Schizophrenia. Biological Psychiatry, Cognitive Neuroscience Approaches to Treatment Development of Impaired Cognition in Schizophrenia: Proceedings of the First Meeting of the CNTRICS Initiative, 64, 40-47.

This article is protected by copyright. All rights reserved 
Caballero, A., Flores-Barrera, E., Cass, D.K., \& Tseng, K.Y. (2014) Differential regulation of parvalbumin and calretinin interneurons in the prefrontal cortex during adolescence. Brain Struct Funct, 219, 395-406.

Caballero, A., Granberg, R., \& Tseng, K.Y. (2016) Mechanisms contributing to prefrontal cortex maturation during adolescence. Neuroscience \& Biobehavioral Reviews, The Adolescent Brain, 70, 4-12.

Cass, D.K., Flores-Barrera, E., Thomases, D.R., Vital, W.F., Caballero, A., \& Tseng, K.Y. (2014) CB1 cannabinoid receptor stimulation during adolescence impairs the maturation of GABA function in the adult rat prefrontal cortex. Molecular Psychiatry, 19, 536-543.

Chattopadhyaya, B., Cristo, G.D., Higashiyama, H., Knott, G.W., Kuhlman, S.J., Welker, E., \& Huang, Z.J. (2004) Experience and Activity-Dependent Maturation of Perisomatic GABAergic Innervation in Primary Visual Cortex during a Postnatal Critical Period. J. Neurosci., 24, 9598-9611.

Chen, C.-Y., Bonham, A.C., Dean, C., Hopp, F.A., Hillard, C.J., \& Seagard, J.L. (2010) Retrograde release of endocannabinoids inhibits presynaptic GABA release to second-order baroreceptive neurons in NTS. Autonomic Neuroscience, 158, 44-50.

Chiu, C.Q., Puente, N., Grandes, P., \& Castillo, P.E. (2010) Dopaminergic Modulation of Endocannabinoid-Mediated Plasticity at GABAergic Synapses in the Prefrontal Cortex. Journal of Neuroscience, 30, 7236-7248.

Clarke, L.E. \& Barres, B.A. (2013) Emerging roles of astrocytes in neural circuit development. Nature Reviews Neuroscience, 14, 311-321.

Craft, R.M., Marusich, J.A., \& Wiley, J.L. (2013) Sex differences in cannabinoid pharmacology: A reflection of differences in the endocannabinoid system? Life Sci, 92, 476-481.

Crozier, R.A., Wang, Y., Liu, C.-H., \& Bear, M.F. (2007) Deprivation-induced synaptic depression by distinct mechanisms in different layers of mouse visual cortex. PNAS, 104, 1383-1388.

Deshmukh, S., Onozuka, K., Bender, K.J., Bender, V.A., Lutz, B., Mackie, K., \& Feldman, D.E. (2007) Postnatal development of cannabinoid receptor type 1 expression in rodent somatosensory

This article is protected by copyright. All rights reserved 
cortex. Neuroscience, 145, 279-287.

Di Cristo, G., Chattopadhyaya, B., Kuhlman, S.J., Fu, Y., Bélanger, M.-C., Wu, C.Z., Rutishauser, U., Maffei, L., \& Huang, Z.J. (2007) Activity-dependent PSA expression regulates inhibitory maturation and onset of critical period plasticity. Nature Neuroscience, 10, 1569-1577.

Di Marzo, V., Stella, N., \& Zimmer, A. (2015) Endocannabinoid signalling and the deteriorating brain. Nat Rev Neurosci, 16, 30-42.

Du, X., Serena, K., Hwang, W.J., Grech, A.M., Wu, Y.W.C., Schroeder, A., \& Hill, R.A. (2018)

Prefrontal cortical parvalbumin and somatostatin expression and cell density increase during adolescence and are modified by BDNF and sex. Molecular and Cellular Neuroscience, 88, 177-188.

Erzurumlu, R.S. \& Gaspar, P. (2012) Development and critical period plasticity of the barrel cortex.

European Journal of Neuroscience, 35, 1540-1553.

Fagiolini, M. \& Hensch, T.K. (2000) Inhibitory threshold for critical-period activation in primary visual cortex. Nature, 404, 183-186.

Fakhoury, M. (2017) Role of the Endocannabinoid System in the Pathophysiology of Schizophrenia. Mol Neurobiol, 54, 768-778.

Ferguson, B.R. \& Gao, W.-J. (2018) PV Interneurons: Critical Regulators of E/I Balance for Prefrontal Cortex-Dependent Behavior and Psychiatric Disorders. Front Neural Circuits, 12, 37.

Fox, K. (1992) A critical period for experience-dependent synaptic plasticity in rat barrel cortex. $J$. Neurosci., 12, 1826-1838.

Fu, Y., Kaneko, M., Tang, Y., Alvarez-Buylla, A., \& Stryker, M.P. (2015) A cortical disinhibitory circuit for enhancing adult plasticity. Elife, 4, e05558.

Fu, Y., Tucciarone, J.M., Espinosa, J.S., Sheng, N., Darcy, D.P., Nicoll, R.A., Huang, Z.J., \& Stryker, M.P. (2014) A Cortical Circuit for Gain Control by Behavioral State. Cell, 156, 1139-1152.

Fuchs, J.L. \& Salazar, E. (1998) Effects of whisker trimming on GABAA receptor binding in the barrel cortex of developing and adult rats. Journal of Comparative Neurology, 395, 209-216.

This article is protected by copyright. All rights reserved 
Fung, S.J., Webster, M.J., Sivagnanasundaram, S., Duncan, C., Elashoff, M., \& Weickert, C.S. (2010) Expression of Interneuron Markers in the Dorsolateral Prefrontal Cortex of the Developing Human and in Schizophrenia. AJP, 167, 1479-1488.

Garcia-Rill, E. (2017) Bottom-up gamma and stages of waking. Medical Hypotheses, 104, 58-62.

Glass, M., Dragunow, M., \& Faull, R.L. (1997) Cannabinoid receptors in the human brain: a detailed anatomical and quantitative autoradiographic study in the fetal, neonatal and adult human brain. Neuroscience, 77, 299-318.

Gomes, F.V., Edelson, J.R., Volk, D.W., \& Grace, A.A. (2018) Altered brain cannabinoid 1 receptor mRNA expression across postnatal development in the MAM model of schizophrenia. Schizophrenia Research, 201, 254-260.

Gómez-Gonzalo, M., Navarrete, M., Perea, G., Covelo, A., Martín-Fernández, M., Shigemoto, R., Luján, R., \& Araque, A. (2015) Endocannabinoids Induce Lateral Long-Term Potentiation of Transmitter Release by Stimulation of Gliotransmission. Cereb Cortex, 25, 3699-3712.

Gordon, J.A. \& Stryker, M.P. (1996) Experience-dependent plasticity of binocular responses in the primary visual cortex of the mouse. J. Neurosci., 16, 3274-3286.

Han, J., Kesner, P., Metna-Laurent, M., Duan, T., Xu, L., Georges, F., Koehl, M., Abrous, D.N., Mendizabal-Zubiaga, J., Grandes, P., Liu, Q., Bai, G., Wang, W., Xiong, L., Ren, W., Marsicano, G., \& Zhang, X. (2012) Acute Cannabinoids Impair Working Memory through Astroglial CB1 Receptor Modulation of Hippocampal LTD. Cell, 148, 1039-1050.

Hanover, t J.L., Huang, Z.J., Tonegawa, S., \& Stryker, M.P. (1999) t Brain-Derived Neurotrophic Factor Overexpression Induces Precocious Critical Period in Mouse Visual Cortex. The Journal of Neuroscience, 19, RC40 LP-RC40.

Hashimoto, T., Nguyen, Q.L., Rotaru, D., Keenan, T., Arion, D., Beneyto, M., Gonzalez-Burgos, G., \& Lewis, D.A. (2009) Protracted Developmental Trajectories of GABAA Receptor $\alpha 1$ and $\alpha 2$ Subunit Expression in Primate Prefrontal Cortex. Biological Psychiatry, The Interplay of GABA, Glutamate, and Dopamine in Schizophrenia and Its Treatment, 65, 1015-1023.

This article is protected by copyright. All rights reserved 
He, H.-Y., Hodos, W., \& Quinlan, E.M. (2006) Visual Deprivation Reactivates Rapid Ocular Dominance Plasticity in Adult Visual Cortex. J. Neurosci., 26, 2951-2955.

He, H.-Y., Ray, B., Dennis, K., \& Quinlan, E.M. (2007) Experience-dependent recovery of vision following chronic deprivation amblyopia. Nature Neuroscience, 10, 1134-1136.

Hedrich, J., Angamo, E.A., Conrad, A., Lutz, B., \& Luhmann, H.J. (2020) Cell type specific impact of cannabinoid receptor signaling in somatosensory barrel map formation in mice. J Comp Neurol, 528, $3-13$.

Heifets, B.D. \& Castillo, P.E. (2009) Endocannabinoid Signaling and Long-Term Synaptic Plasticity. Annual Review of Physiology, 71, 283-306.

Hennes, M., Lombaert, N., Wahis, J., Haute, C.V. den, Holt, M.G., \& Arckens, L. (2020) Astrocytes shape the plastic response of adult cortical neurons to vision loss. Glia, 68, 2102-2118.

Hensch, T.K. (2005) Critical period plasticity in local cortical circuits. Nature Reviews Neuroscience, 6, 877-888.

Hensch, T.K. \& Bilimoria, P.M. (2012) Re-opening Windows: Manipulating Critical Periods for Brain Development. Cerebrum, 2012.

Hensch, T.K., Fagiolini, M., Mataga, N., Stryker, M.P., Baekkeskov, S., \& Kash, S.F. (1998) Local GABA Circuit Control of Experience-Dependent Plasticity in Developing Visual Cortex. Science, 282, 1504 LP - 1508 .

Hillard, C.J. (2015) Endocannabinoids and the Endocrine System in Health and Disease. In Pertwee, R.G. (ed), Endocannabinoids, Handbook of Experimental Pharmacology. Springer International Publishing, Cham, pp. 317-339.

Hu, W., MacDonald, M.L., Elswick, D.E., \& Sweet, R.A. (2015) The glutamate hypothesis of schizophrenia: evidence from human brain tissue studies. Annals of the New York Academy of Sciences, 1338, 38-57.

Huang, S., Gu, Y., Quinlan, E.M., \& Kirkwood, A. (2010) A Refractory Period for Rejuvenating GABAergic Synaptic Transmission and Ocular Dominance Plasticity with Dark Exposure. Journal of

This article is protected by copyright. All rights reserved 
Neuroscience, 30, 16636-16642.

Huang, S. \& Kirkwood, A. (2020) Endocannabinoid Signaling Contributes to Experience-Induced Increase of Synaptic Release Sites From Parvalbumin Interneurons in Mouse Visual Cortex. Front. Cell. Neurosci., 14.

Hurd, Y.L., Michaelides, M., Miller, M.L., \& Jutras-Aswad, D. (2014) Trajectory of adolescent cannabis use on addiction vulnerability. Neuropharmacology, 76, 416-424.

Jiang, B., Huang, S., de Pasquale, R., Millman, D., Song, L., Lee, H.-K., Tsumoto, T., \& Kirkwood, A. (2010) The Maturation of GABAergic Transmission in Visual Cortex Requires EndocannabinoidMediated LTD of Inhibitory Inputs during a Critical Period. Neuron, 66, 248-259.

Jiang, B., Huang, Z.J., Morales, B., \& Kirkwood, A. (2005) Maturation of GABAergic transmission and the timing of plasticity in visual cortex. Brain Research Reviews, 50, 126-133.

Keimpema, E., Alpár, A., Howell, F., Malenczyk, K., Hobbs, C., Hurd, Y.L., Watanabe, M., Sakimura, K., Kano, M., Doherty, P., \& Harkany, T. (2013) Diacylglycerol lipase a manipulation reveals developmental roles for intercellular endocannabinoid signaling. Scientific Reports, 3, 2093.

Kreitzer, A. (2002) Retrograde signaling by endocannabinoids. Current Opinion in Neurobiology, 12, 324-330.

Lafourcade, M., Elezgarai, I., Mato, S., Bakiri, Y., Grandes, P., \& Manzoni, O.J. (2007) Molecular Components and Functions of the Endocannabinoid System in Mouse Prefrontal Cortex. PLoS One, 2.

Larsen, B. \& Luna, B. (2018) Adolescence as a neurobiological critical period for the development of higher-order cognition. Neuroscience \& Biobehavioral Reviews, 94, 179-195.

Le Vay, S., Wiesel, T.N., \& Hubel, D.H. (1980) The development of ocular dominance columns in normal and visually deprived monkeys. Journal of Comparative Neurology, 191, 1-51.

Le Magueresse, C. \& Monyer, H. (2013) GABAergic Interneurons Shape the Functional Maturation of the Cortex. Neuron, 77, 388-405.

Levelt, C.N. \& Hübener, M. (2012) Critical-Period Plasticity in the Visual Cortex. Annual Review of

This article is protected by copyright. All rights reserved 
Neuroscience, 35, 309-330.

Leweke, F.M., Mueller, J.K., Lange, B., Fritze, S., Topor, C.E., Koethe, D., \& Rohleder, C. (2018) Role of the Endocannabinoid System in the Pathophysiology of Schizophrenia: Implications for Pharmacological Intervention. CNS Drugs, 32, 605-619.

Li, L., Bender, K.J., Drew, P.J., Jadhav, S.P., Sylwestrak, E., \& Feldman, D.E. (2009)

Endocannabinoid Signaling Is Required for Development and Critical Period Plasticity of the Whisker Map in Somatosensory Cortex. Neuron, 64, 537-549.

Lisman, J. (2012) Excitation, inhibition, local oscillations, or large-scale loops: what causes the symptoms of schizophrenia? Current Opinion in Neurobiology, Synaptic structure and function, 22, $537-544$.

Lovelace, J.W., Corches, A., Vieira, P.A., Hiroto, A.S., Mackie, K., \& Korzus, E. (2015) An animal model of female adolescent cannabinoid exposure elicits a long-lasting deficit in presynaptic longterm plasticity. Neuropharmacology, 99, 242-255.

Maffei, A. (2011) The Many Forms and Functions of Long Term Plasticity at GABAergic Synapses [WWW Document]. Neural Plasticity,. URL https://www.hindawi.com/journals/np/2011/254724/

Maglio, L.E., Noriega-Prieto, J.A., Maraver, M.J., \& Fernández de Sevilla, D. (2018)

Endocannabinoid-Dependent Long-Term Potentiation of Synaptic Transmission at Rat Barrel Cortex. Cereb Cortex, 28, 1568-1581.

Manrique-Garcia, E., Zammit, S., Dalman, C., Hemmingsson, T., Andreasson, S., \& Allebeck, P. (2012) Cannabis, schizophrenia and other non-affective psychoses: 35 years of follow-up of a population-based cohort. Psychological Medicine, 42, 1321-1328.

Mei, Y.-Y., Wu, D.C., \& Zhou, N. (2018) Astrocytic Regulation of Glutamate Transmission in Schizophrenia. Front Psychiatry, 9.

Metna-Laurent, M. \& Marsicano, G. (2015) Rising stars: Modulation of brain functions by astroglial type-1 cannabinoid receptors: Astroglial $\mathrm{CB}_{1}$ Receptor Functions. Glia, 63, 353-364.

Min, R. \& Nevian, T. (2012) Astrocyte signaling controls spike timing-dependent depression at 
neocortical synapses. Nature Neuroscience, 15, 746-753.

Morales, B., Choi, S.-Y., \& Kirkwood, A. (2002a) Dark Rearing Alters the Development of GABAergic Transmission in Visual Cortex. The Journal of Neuroscience, 22, 8084 LP - 8090.

Morales, B., Choi, S.-Y., \& Kirkwood, A. (2002b) Dark Rearing Alters the Development of GABAergic Transmission in Visual Cortex. The Journal of Neuroscience, 22, 8084-8090.

Moretto, E., Murru, L., Martano, G., Sassone, J., \& Passafaro, M. (2018) Glutamatergic synapses in neurodevelopmental disorders. Progress in Neuro-Psychopharmacology and Biological Psychiatry, Synaptic Basis of Mental Illness, 84, 328-342.

Morris, H.M., Hashimoto, T., \& Lewis, D.A. (2008) Alterations in Somatostatin mRNA Expression in the Dorsolateral Prefrontal Cortex of Subjects with Schizophrenia or Schizoaffective Disorder. Cereb Cortex, 18, 1575-1587.

Moshfeghi, D.M., Moshfeghi, A.A., \& Finger, P.T. (2000) Enucleation. Survey of Ophthalmology, 44, 277-301.

Mulder, J., Aguado, T., Keimpema, E., Barabás, K., Rosado, C.J.B., Nguyen, L., Monory, K., Marsicano, G., Marzo, V.D., Hurd, Y.L., Guillemot, F., Mackie, K., Lutz, B., Guzmán, M., Lu, H.-C., Galve-Roperh, I., \& Harkany, T. (2008) Endocannabinoid signaling controls pyramidal cell specification and long-range axon patterning. PNAS, 105, 8760-8765.

Murase, S., Lantz, C.L., \& Quinlan, E.M. (2017) Light reintroduction after dark exposure reactivates plasticity in adults via perisynaptic activation of MMP-9. eLife, 6 , e27345.

Nys, J., Aerts, J., Ytebrouck, E., Vreysen, S., Laeremans, A., \& Arckens, L. (2014) The cross-modal aspect of mouse visual cortex plasticity induced by monocular enucleation is age dependent: Enucleation-induced visual cortex plasticity. Journal of Comparative Neurology, 522, 950-970.

Nys, J., Smolders, K., Laramee, M.-E., Hofman, I., Hu, T.-T., \& Arckens, L. (2015) Regional Specificity of GABAergic Regulation of Cross-Modal Plasticity in Mouse Visual Cortex after Unilateral Enucleation. Journal of Neuroscience, 35, 11174-11189.

Oliveira da Cruz, J.F., Robin, L.M., Drago, F., Marsicano, G., \& Metna-Laurent, M. (2016) Astroglial

This article is protected by copyright. All rights reserved 
type-1 cannabinoid receptor (CB1): A new player in the tripartite synapse. Neuroscience, 323, 35-42.

Perea, G., Navarrete, M., \& Araque, A. (2009) Tripartite synapses: astrocytes process and control synaptic information. Trends in Neurosciences, 32, 421-431.

Petrus, E., Rodriguez, G., Patterson, R., Connor, B., Kanold, P.O., \& Lee, H.-K. (2015) Vision Loss Shifts the Balance of Feedforward and Intracortical Circuits in Opposite Directions in Mouse Primary Auditory and Visual Cortices. J. Neurosci., 35, 8790-8801.

Piekarski, D.J., Boivin, J.R., \& Wilbrecht, L. (2017) Ovarian Hormones Organize the Maturation of Inhibitory Neurotransmission in the Frontal Cortex at Puberty Onset in Female Mice. Current Biology, 27, 1735-1745.e3.

Piomelli, D. (2003) The molecular logic of endocannabinoid signalling. Nature Reviews Neuroscience, 4, 873-884.

Ramamoorthi, K. \& Lin, Y. (2011) The contribution of GABAergic dysfunction to neurodevelopmental disorders. Trends in Molecular Medicine, 17, 452-462.

Reh, R.K., Dias, B.G., Nelson, C.A., Kaufer, D., Werker, J.F., Kolb, B., Levine, J.D., \& Hensch, T.K. (2020) Critical period regulation across multiple timescales. PNAS, 117, 23242-23251.

Renard, J., Vitalis, T., Rame, M., Krebs, M.-O., Lenkei, Z., Le Pen, G., \& Jay, T.M. (2016) Chronic cannabinoid exposure during adolescence leads to long-term structural and functional changes in the prefrontal cortex. European Neuropsychopharmacology, 26, 55-64.

Rodríguez de Fonseca, F., Ramos, J.A., Bonnin, A., \& Fernández-Ruiz, J.J. (1993) Presence of cannabinoid binding sites in the brain from early postnatal ages. Neuroreport, 4, 135-138.

Saito, A., Ballinger, M.D.L., Pletnikov, M.V., Wong, D.F., \& Kamiya, A. (2013) Endocannabinoid system: Potential novel targets for treatment of schizophrenia. Neurobiology of Disease, What clinical findings can teach us about the neurobiology of schizophrenia?, 53, 10-17.

Sass, L.A. (2013) Self-disturbance and schizophrenia: Structure, specificity, pathogenesis. Recherches en psychanalyse, $\mathbf{n}^{\circ} \mathbf{1 6}, 119-132$.

This article is protected by copyright. All rights reserved 
Scheyltjens, I. \& Arckens, L. (2016) The Current Status of Somatostatin-Interneurons in Inhibitory Control of Brain Function and Plasticity. Neural Plasticity, 2016, 1-20.

Scheyltjens, I., Vreysen, S., Van den Haute, C., Sabanov, V., Balschun, D., Baekelandt, V., \& Arckens, L. (2018) Transient and localized optogenetic activation of somatostatin-interneurons in mouse visual cortex abolishes long-term cortical plasticity due to vision loss. Brain Struct Funct, 223, 2073-2095.

Schultz, S., Siniscalco, D., 1 Department of Cellular and Integrative Physiology, School of Medicine, University of Texas Health Science Center San Antonio, San Antonio, TX 78229, USA, 2

Department of Experimental Medicine, University of Campania, 80138 Naples, Italy, 3 Italian Group for Study Autism-GISA, 25018 Brescia, Italy, \& 4 Centre for Autism-La Forza del Silenzio, 81036 Caserta, Italy (2019) Endocannabinoid system involvement in autism spectrum disorder: An overview with potential therapeutic applications. AIMS Molecular Science, 6, 27-37.

Setlur, V.J., Parikh, J.G., \& Rao, N.A. (2010) Changing causes of enucleation over the past 60 years. Graefes Arch Clin Exp Ophthalmol, 248, 593-597.

Shen, M., Piser, T.M., Seybold, V.S., \& Thayer, S.A. (1996) Cannabinoid Receptor Agonists Inhibit Glutamatergic Synaptic Transmission in Rat Hippocampal Cultures. J. Neurosci., 16, 4322-4334.

Skosnik, P.D., Cortes-Briones, J.A., \& Hajós, M. (2016) It's All in the Rhythm: The Role of Cannabinoids in Neural Oscillations and Psychosis. Biol Psychiatry, 79, 568-577.

Skosnik, P.D., Krishnan, G.P., D’Souza, D.C., Hetrick, W.P., \& O’Donnell, B.F. (2014) Disrupted Gamma-Band Neural Oscillations During Coherent Motion Perception in Heavy Cannabis Users. Neuropsychopharmacology, 39, 3087-3099.

Sugiyama, S., Di Nardo, A.A., Aizawa, S., Matsuo, I., Volovitch, M., Prochiantz, A., \& Hensch, T.K. (2008) Experience-Dependent Transfer of Otx2 Homeoprotein into the Visual Cortex Activates Postnatal Plasticity. Cell, 134, 508-520.

Sun, W., Wang, L., Li, S., Tie, X., \& Jiang, B. (2015) Layer-specific endocannabinoid-mediated longterm depression of GABAergic neurotransmission onto principal neurons in mouse visual cortex.

This article is protected by copyright. All rights reserved 
European Journal of Neuroscience, 42, 1952-1965.

Szabo, G.G., Lenkey, N., Holderith, N., Andrasi, T., Nusser, Z., \& Hajos, N. (2014) Presynaptic Calcium Channel Inhibition Underlies CB1 Cannabinoid Receptor-Mediated Suppression of GABA Release. Journal of Neuroscience, 34, 7958-7963.

Tang, Y., Stryker, M.P., Alvarez-Buylla, A., \& Espinosa, J.S. (2014) Cortical plasticity induced by transplantation of embryonic somatostatin or parvalbumin interneurons. PNAS, 111, 18339-18344.

Tseng, K.-Y. \& O’Donnell, P. (2007) Dopamine Modulation of Prefrontal Cortical Interneurons Changes during Adolescence. Cereb Cortex, 17, 1235-1240.

Van Brussel, L., Gerits, A., \& Arckens, L. (2011) Evidence for Cross-Modal Plasticity in Adult Mouse Visual Cortex Following Monocular Enucleation. Cerebral Cortex, 21, 2133-2146.

van den Heuvel, M.P. \& Fornito, A. (2014) Brain Networks in Schizophrenia. Neuropsychol Rev, 24, $32-48$.

van Os, J., Bak, M., Hanssen, M., Bijl, R.V., de Graaf, R., \& Verdoux, H. (2002) Cannabis Use and Psychosis: A Longitudinal Population-based Study. Am J Epidemiol, 156, 319-327.

Viveros, M.-P., Marco, E.M., López-Gallardo, M., Garcia-Segura, L.M., \& Wagner, E.J. (2011) Framework for sex differences in adolescent neurobiology: A focus on cannabinoids. Neuroscience \& Biobehavioral Reviews, Passing the Knife Edge in Adolescence: Brain Pruning and Specification of Individual Lines of Development, 35, 1740-1751.

Wagner, E.J. (2016) Sex Differences in Cannabinoid-Regulated Biology: A Focus on Energy Homeostasis. Front Neuroendocrinol, 40, 101-109.

Wang, L., Liu, J., Harvey-White, J., Zimmer, A., \& Kunos, G. (2003) Endocannabinoid signaling via cannabinoid receptor 1 is involved in ethanol preference and its age-dependent decline in mice. Proc Natl Acad Sci U S A, 100, 1393-1398.

Webster, M.J., Weickert, C.S., Herman, M.M., \& Kleinman, J.E. (2002) BDNF mRNA expression during postnatal development, maturation and aging of the human prefrontal cortex. Developmental Brain Research, 139, 139-150. 
Welker, E., Soriano, E., Dörfl, J., \& Van der Loos, H. (1989) Plasticity in the barrel cortex of the adult mouse: transient increase of GAD-immunoreactivity following sensory stimulation. Exp Brain Res, 78, 659-664.

Wiesel, T.N. (1982) Postnatal development of the visual cortex and the influence of environment. Nature, 299, 583-591.

Wiesel, T.N. \& Hubel, D.H. (1965) EXTENT OF RECOVERY FROM THE EFFECTS OF VISUAL DEPRIVATION IN KITTENS. Journal of Neurophysiology, 28, 1060-1072.

Wu, C.-S., Zhu, J., Wager-Miller, J., Wang, S., O’Leary, D., Monory, K., Lutz, B., Mackie, K., \& Lu, H.-C. (2010) Requirement of cannabinoid CB1 receptors in cortical pyramidal neurons for appropriate development of corticothalamic and thalamocortical projections. European Journal of Neuroscience, 32, 693-706.

Yaeger, C.E., Ringach, D.L., \& Trachtenberg, J.T. (2019) Neuromodulatory control of localized dendritic spiking in critical period cortex. Nature, 567, 100-104.

Yavorska, I. \& Wehr, M. (2016) Somatostatin-Expressing Inhibitory Interneurons in Cortical Circuits. Frontiers in Neural Circuits, 10.

Yeh, M.L., Selvam, R., \& Levine, E.S. (2017) BDNF-induced endocannabinoid release modulates neocortical glutamatergic neurotransmission. Synapse, 71, e21962.

Yildiz, M., Borgwardt, S.J., \& Berger, G.E. (2011) Parietal Lobes in Schizophrenia: Do They Matter? [WWW Document]. Schizophrenia Research and Treatment,. URL https://www.hindawi.com/journals/schizort/2011/581686/

Yoneda, T., Kameyama, K., Esumi, K., Daimyo, Y., Watanabe, M., \& Hata, Y. (2013)

Developmental and Visual Input-Dependent Regulation of the CB1 Cannabinoid Receptor in the Mouse Visual Cortex. PLoS ONE, 8, e53082.

Zamberletti, E., Rubino, T., \& Parolaro, D. (2012) The Endocannabinoid System and Schizophrenia: Integration of Evidence. Current Pharmaceutical Design, 18, 4980-4990.

Zammit, S., Allebeck, P., Andreasson, S., Lundberg, I., \& Lewis, G. (2002) Self reported cannabis 
use as a risk factor for schizophrenia in Swedish conscripts of 1969: historical cohort study. BMJ, 325, 1199.
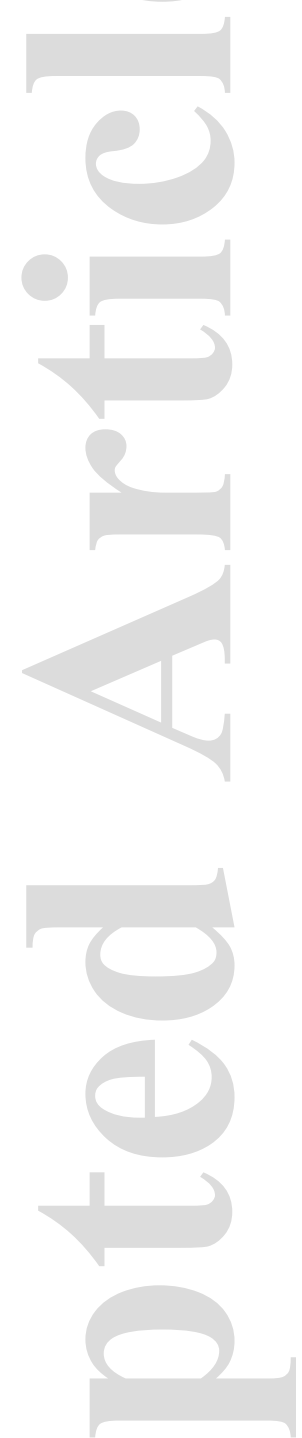

This article is protected by copyright. All rights reserved 


\section{Conflict of Interest}

None

\section{Author contributions}

Lucas Durieux: Conceptualization, Writing

Sara Gilissen: Conceptualization, Writing

Lutgarde Arckens: Conceptualization, Resources, Writing, Supervision, Funding acquisition

\section{Role of the funding source}

This work was supported by the KU Leuven Research Council (C14/16/048) and the Research Foundation Flanders (FWO), Belgium via research project funding (G061216N) and a doctoral fellowship L. Durieux (SB/1S62920N) and S. Gilissen (SB/151597). The funding sources had no involvement in study design, collection, analyses and interpretation of the data or in actively writing this paper.

\section{Acknowledgments}

All figures were created with biorender.com.

\section{Data availability}

All data are available in the main text.

This article is protected by copyright. All rights reserved 
DREADD

E/l

KO

OD

V1

\section{Designer Receptor Exclusively Activated by Designer Drugs}

Excitation/Inhibition

Knock-Out

Ocular dominance

Primary visual cortex

\section{ELECTROPHYSIOLOGY}

EPSP

iLTD

IPSC

LTD

LTP

t-LTD
Excitatory postsynaptic potential

Inhibitory long-term depression

Inhibitory postsynaptic current

Long-term depression

Long-term potentiation

Spike timing dependent depression

\section{PHARMACOLOGICAL COMPOUNDS}

MPEP

SR

WIN
2-Methyl-6-(phenylethynyl)pyridine

\section{SR141716A}

WIN 55215-1

\section{GABAERGIC SYSTEM}

GABA

$\mathrm{GABA}_{\mathrm{A}}$

GAD

SOM

PV

VIP
Y-aminobutyric acid

GABA receptor $A$

glutamic acid decarboxylase

Somatostatin

Parvalbumin

Vasoactive intestinal polypeptide

\section{ENDOCANNABINOID SYSTEM}


2-AG

CB1R (Cnr1)

CB2R

ECB

FAAH
2-Arachidonoylglycerol

Cannabinoid receptor type 1

Cannabinoid receptor type 2

Endocannabinoid

Fatty acid amide hydrolase

\section{GLUTAMATERGIC SYSTEM}

mGluR2/3/5

NMDA receptor
Metabotropic glutamate receptor 2, 3 and 5

$\mathrm{N}$-methyl-D-asparate receptor

Table 1 - Abbreviations

This article is protected by copyright. All rights reserved 


\section{Figure 1 - Critical periods of cortical plasticity throughout life.}

The timing of critical periods of heightened cortical plasticity follows inhibitory maturation in the specific cortical areas in mammals, including humans (upper blue, red and green gradients). P0 to P120 represents post-natal days in rodents, corresponding to the human life phases 'childhood', 'adolescence' and 'adulthood'. In mice, the critical period of the primary somatosensory cortex (Sts; blue line) occurs in the first two weeks post birth (P0), followed by the critical period of ocular dominance plasticity in the visual cortex, starting from eye-opening (P14) to P35 (red line). Sensory cortex plasticity is also present in adulthood, reflecting a similar response as the critical period although to a lesser degree. A well-studied example of adult visual cortex plasticity is cross-modal plasticity. Maturation of association cortices (green line), like prefrontal cortex, takes place during adolescence (P35-P60 in mice), and is associated to a vulnerability period (light-blue background) to cannabis use, associated with a higher risk to develop schizophrenia. Endocannabinoids (ECBs) regulate major phenomena during each critical period, like sensory map formation (as exemplified for the barrel cortex, blue), loss of iLTD (red) and refinement of synaptic transmission strength (green).

\section{Figure 2 - Endocannabinoid-mediated short and long term plasticity}

$(\mathbf{A}, \mathbf{B})$ Synthesis and degradation pathways of the two main CB1R ligands 2-Arachidonoylglycerol (2AG) (A) and anandamide (B). On demand synthesis of both ligands, and degradation of Anandamide upon re-uptake, happens in the postsynaptic element (grey background) (B). Degradation of 2-AG happens in the presynaptic element (blue background) of the synapse (A).

(C) Depolarization of a postsynaptic neuron, induced via activation of glutamatergic receptors, leads to the activation of voltage-dependent calcium $\left(\mathrm{Ca}^{2+}\right)$ channels. $\mathrm{Ca}^{2+}$ influx provokes synthesis of endocannabinoids (ECBs), like Anandamide and 2-AG, that, when released, activate presynaptic CB1R. Presynaptic $\mathrm{CB} 1 \mathrm{R}$ then inhibits the $\mathrm{Ca}^{2+}$-induced exocytosis of neurotransmitters from the presynapse, such as glutamate or GABA. This results in depolarization-induced suppression of excitation (DSE) via inhibition of Glutamate release (left) and depolarization-induced suppression of inhibition (DSI) via inhibition of GABA release (right).

(D) In the context of long-term depression, presynaptic CB1R-Gai/o activation on an excitatory terminal (left) downregulates the cAMP/PKA pathway and results in the inhibition of glutamate release. On an inhibitory terminal (right), the same pathway is downregulated and results in the dephosphorylation of an unknown presynaptic target (PST) and causes the inhibition of GABA release. The pre-synaptic proteins Rab3B and RIM1 $\alpha$ have also been shown to be involved in ECB-iLTD (not represented here).

AC: adenyl cyclase; cAMP: adenyl cyclase pathway; PKA: protein kinase A; CaN: calcineurin.; PLC: phospholipase C; PLA1: phospholipase A1; DAGL: Diacylglycerol lipase; PI: phosphatidylinositol; 
MAGL: Monoacylglycerol lipase; FAAH: Fatty acid amide hydrolase; AA: arachidonic acid; 1,2-DAG: 1,2-diacylglycerol.

Figure 3 - GABAergic interneuron types implicated in cortical critical period plasticity (A) and in schizophrenia (B) and implication of endocannabinoids

(A) In the cortex, parvalbumin $\left(\mathrm{PV}^{+}\right)$interneurons (purple) can be a chandelier (ChPV) or basket (bPV) type. ChPV cells inhibit the axon initial segment and regulate the output of pyramidal neurons through their GAT1 cartridges (green square). bPV cells inhibit the soma and proximal dendrites of PNs. bPV cells are essential for early critical periods: during the increase in inhibition, they acquire fastspiking properties and become progressively enwrapped with a perineural net. Somatostatin ( $\mathrm{SOM}^{+}$, green) interneurons can influence pyramidal neuron output directly at distal dendrites and indirectly by inducing disinhibition via $\mathrm{PV}^{+}$cells. $\mathrm{SOM}^{+}$cell maturation happens when critical periods peak. During adult cortical plasticity, the $\mathrm{PV}^{+}$and $\mathrm{SOM}^{+}$cells are also required to reopen windows of cortical plasticity. The role of $\mathrm{SOM}^{+}$cells is important when adult plasticity is induced by sensory loss, modulating inter-cortical connections to promote cross-modal plasticity. Astrocytes (blue) are a third component at tripartite synapses and regulate synaptic transmission through the release of gliotransmitters. Yellow squares emphasize the different synaptic contacts of interneurons that express CB1R, and thus show where the ECB system could be involved in cortical excitability.

(B) In schizophrenia, cortical PV expression is decreased. bPV cell signaling is hampered due to a decreased postsynaptic pyramidal GABA alpha-1 subunit expression, and an increase of $\mu$ Opioid receptor $(\mu \mathrm{OR}) \mathrm{mRNA}$ expression is observable at their presynaptic site (Middle large grey square).

The bPV cells are associated with gamma oscillations, which are disturbed in schizophrenic patients. $\mathrm{SOM}^{+}$cells synaptic transmission also seems hampered because of a decreased expression of the postsynaptic somatostatin receptor 2 (SSTR2) (Top large grey square). Information about astrocyte dysregulation remains mixed for now. Yellow squares emphasize the different synaptic contacts of interneurons that express CB1R, and thus show where the ECB system could be involved in the cortical excitability dysregulation in schizophrenia, and how this is relevant for the treatment of this conditionThe $\mathrm{CCK}^{+}$interneuron subclass (orange) in which $\mathrm{CB} 1 \mathrm{R}$ is mostly expressed displays decreased expression of CCK and CB1R mRNA.

\section{Figure 4 - Neocortex plasticity and the endocannabinoid system}

Endocannabinoid involvement in plasticity of the prefrontal, somatosensory and visual cortex. The studied animal species are specified with a circled M (orange) for mouse and R (green) for rat. 


\section{Figure 5 - Impact of CB1R manipulation on long-term synaptic plasticity}

Experimental setup, post-synaptic event and endocannabinoid involvement in LTP, LTD, t-LTD and iLTD. Pre-synaptic red neurons are excitatory and blue pre-synaptic neurons are inhibitory. A large red lightning illustrates an enhancement of the excitatory post-synaptic potentials (EPSP), while a small one stands for a reduction. Blue small lightning illustrates a decrease of inhibitory post-synaptic potentials (IPSP). ECB involvement is summarized in the right column, demonstrated by examples from different studies.

LTP: Long-term potentiation; LTD: Long-term depression; iLTD: Inhibitory long-term depression; tLTD: Spike timing-dependent long-term depression; S1: primary somatosensory cortex; VC: Visual cortex; PFC: Prefrontal cortex; MAGL: Monoacylglycerol lipase.

Table 1 - Abbreviations 


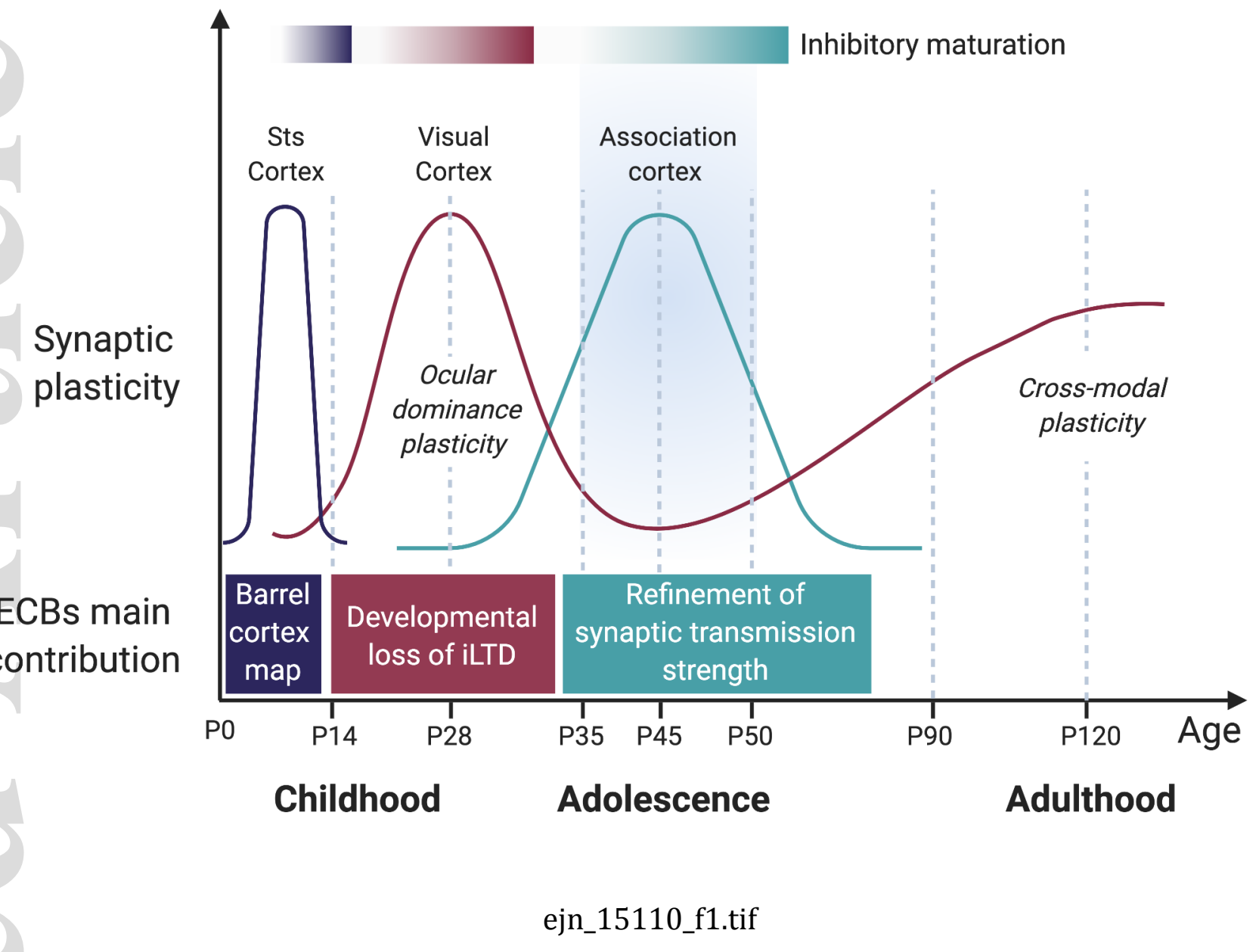

This article is protected by copyright. All rights reserved 


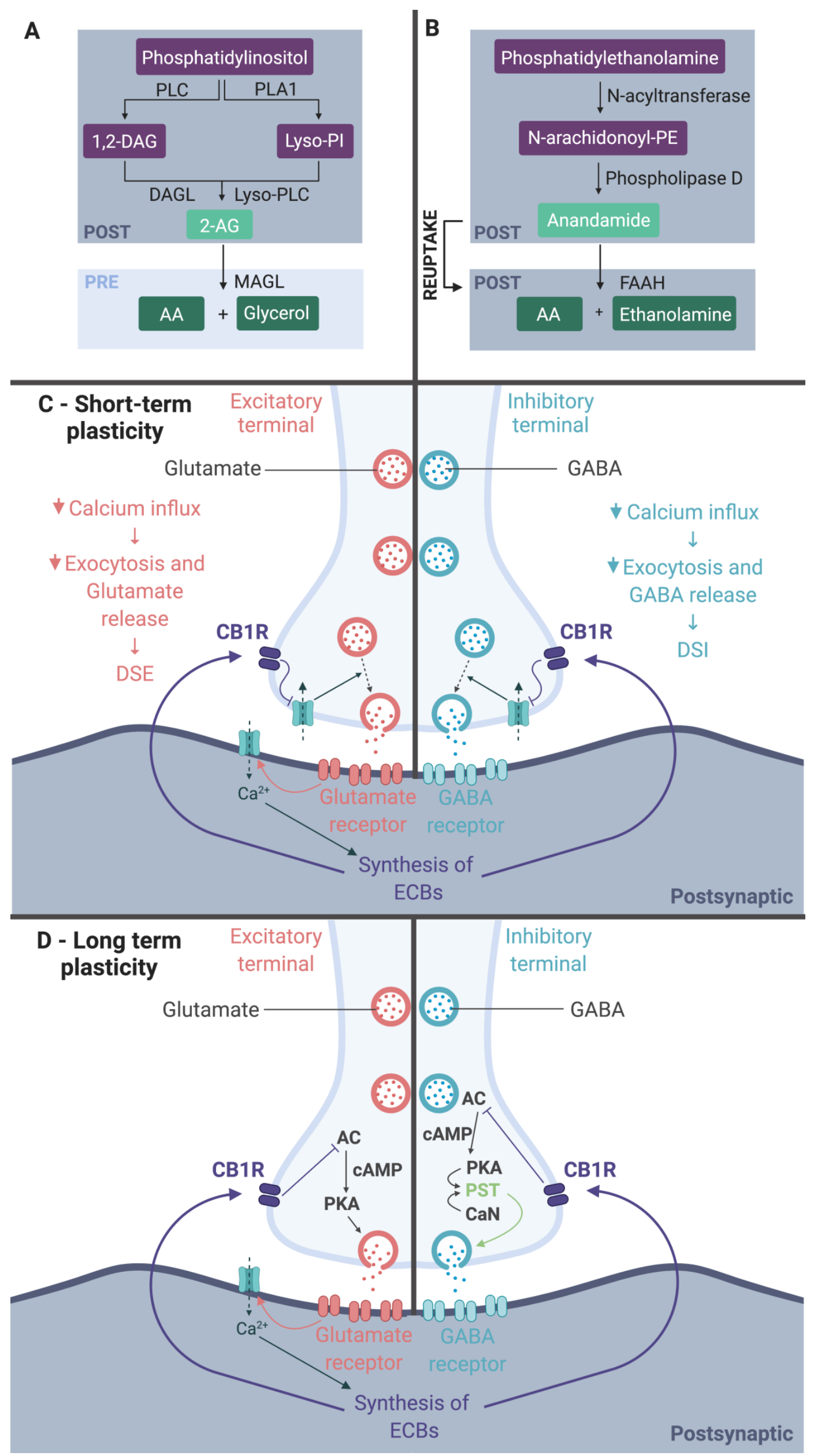

This article is protected by copyright. All rights reserved 


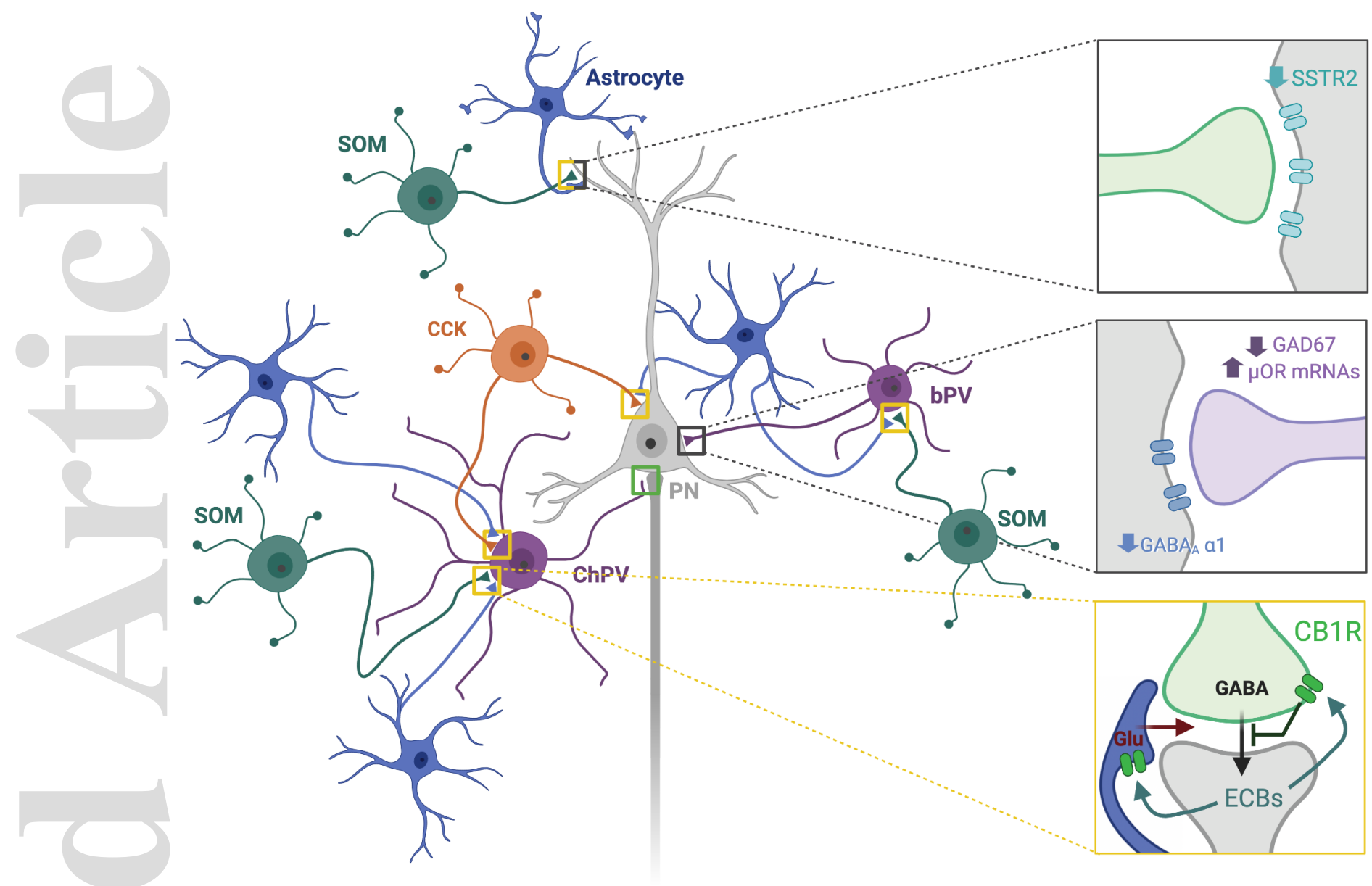

ejn_15110_f3.tif

This article is protected by copyright. All rights reserved 


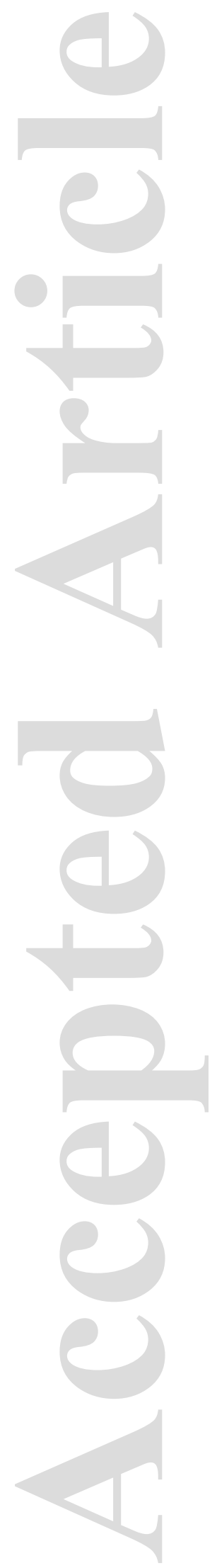

Prefrontal Cortex

- Dendritic length, density and complexity of $\mathrm{L} 2 / 3$ pyramidal neurons $\mathbf{R}$

- LTD R

- mGluR2/3 mediated LTD M

- LTP R

- GABAergic IPSC $\mathbf{R}$

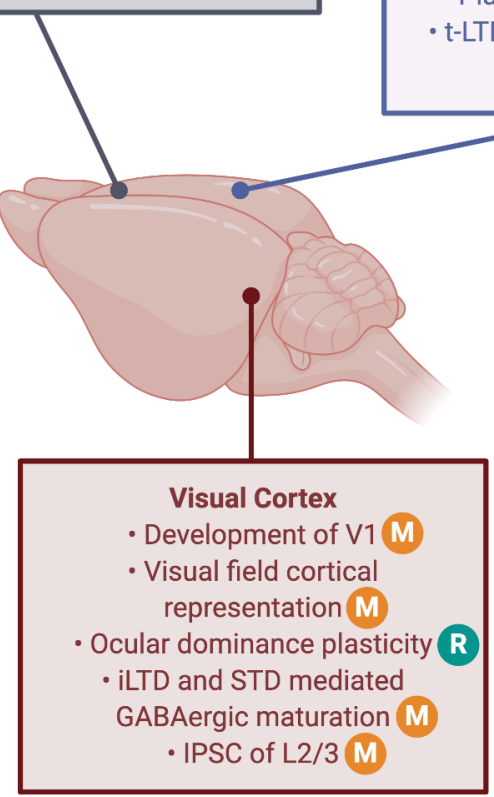

Somatosensory Cortex

- Development of S1 R

- Development of the barrel map M

- Development of the CTAs and TCAs M

- Plasticity of L2/3-L4 synapses $\mathbf{R}$

t-LTD induced increase of $\mathrm{Ca}^{2+}$ in astrocytes $\mathbf{R}$

ejn_15110_f4.tif 
